\title{
Myocardial biomarkers for prediction of cardiovascular disease
}

\author{
Johan Sundström* \\ Department of Medical Sciences, Uppsala University, Uppsala, Sweden
}

\begin{abstract}
The identification of those persons in the population who have the highest risk of future cardiovascular events is important for targeting intensive preventive efforts. This can be reliably done using a handful of long since established risk factors. The unmet need for new molecular biomarkers for prediction of cardiovascular events in the general population is therefore low. In order for a new biomarker to be used clinically for risk prediction, a statistically significant association of levels of the biomarker to adverse outcome is not enough, but the biomarker should also be demonstrated to add discriminative capacity beyond established risk factors. In contrast to the limited value of new biomarkers for risk prediction, their usefulness for unraveling the pathophysiology of cardiovascular disease is large. The myocardium is the source of a vast number of interesting biomarkers, of which a few may be useful for risk prediction in the general population. Two of these, troponin-I and the N-terminal fragment of brain natriuretic peptide, have passed tests of added discriminatory value. Numerous other biomarkers produced by cardiomyocytes or non-cardiomyocytes in the myocardium are promising, and if they are not proven useful for risk prediction, they will unquestionably enhance our understanding of cardiovascular disease.
\end{abstract}

Keywords: Risk, epidemiology, population, biomarker, peptide, myocardium

\section{The need for prediction and prevention of cardiovascular events}

Cardiovascular diseases kill half of the population in developed countries, and seriously disable a further large number. A high cardiovascular disease death rate in elderly persons is unavoidable, but prevention of cardiovascular deaths in younger individuals is highly prioritized, as recently outlined in the European Heart Health Charter [1].

Sudden cardiac death is sometimes the first manifestation of cardiovascular disease, and traditional risk factors can be identified beforehand in a minority of these persons [2]. Further, one out of four myocardial infarctions resulting in Q-waves are asymptomatic [3], and smaller myocardial infarctions may be asymptomatic

* Corresponding author: Johan Sundström, MD PhD, Department of Medical Sciences, Uppsala University Hospital, SE-751 85 Uppsala, Sweden. Tel.: +4618 6119889 or +46 704225220 ; Fax: +46 18 509297; E-mail: johan.sundstrom@medsci.uu.se. in as much as four out of five victims [4]. Hence, the high risk strategy will not be sufficient in these cases.

In order to prevent as many of premature cardiovascular deaths as possible, the Charter therefore calls for the use of both the population strategy (treating the whole population with measures such as smoking prevention or cessation, physical activity, and fruit and vegetable intake) and the high-risk strategy (identifying persons at high risk and treating risk factors aggressively). This article reviews some of the tools available for the latter strategy.

\subsection{The role of biomarkers in the identification of high-risk persons}

The term risk factor was coined fifty years ago [5], and soon thereafter it was established that the large majority of cardiovascular events can be predicted using a mere handful of risk factors. These include a few molecular biomarkers such as glucose and cholesterol, but the largest part of the equation is accounted for by other markers, such as age, sex, blood pres- 
sure, and smoking. Indeed, the non-modifiable markers are among the most powerful ones. Of the modifiable markers, the non-molecular markers blood pressure and smoking are the most important [6]. Among other non-molecular markers, electrocardiographic left ventricular hypertrophy is one of the most powerful risk factors. Other physiological measures of subclinical cardiovascular disease, such as those obtained by echocardiography, carotid ultrasound or cardiovascular magnetic resonance or computer tomography imaging, are also gaining ground as potential tools for identifying high risk persons.

The term "biomarker" used to include all of the factors mentioned above, but the meaning has recently shifted to merely indicate molecular markers. This is the meaning that will be used in this article. Biomarkers have a role in cardiovascular risk prediction, partly because of risk-predictive capacity of certain markers, but mainly because of accessibility and relatively low cost. Nearly three decades ago, more than 200 variables had been related to coronary disease, [7], and the number has been growing exponentially since then.

The unmet need for new risk factors is low [8]. In fact, a model without any laboratory testing could discriminate subsequent cardiovascular events as precisely as a model with limited laboratory testing (of the most important molecular biomarker, cholesterol) in a population-based sample [9]. One might thus argue that more time and money should be spent on implementing existing guidelines using already established risk factors instead of searching for new risk factors.

Today, new biomarkers have a though case for being considered clinically useful [10]. Demonstrating a statistically significant relation between a new biomarker and a cardiovascular outcome simply isn't enough to take the marker from bench to bedside anymore. Nowadays, demonstration of added power to discriminate those who will suffer cardiovascular events from those who will not is warranted before a marker is considered for clinical use [11].

Although their immediate clinical usefulness may be limited, circulating biomarkers are important tools for increasing the understanding of biological pathways, and may thereby be of indirect clinical importance by e.g. propelling drug discovery. Further, if new biomarkers do not find use as risk prediction markers in the general population, they may help identify subgroups of patients, may be useful for risk prediction in certain clinical settings, and may find use in tailoring and monitoring treatment. Very few of the biomarkers reviewed in this article have passed reasonable tests of usefulness [10] and even fewer the tests of discriminatory capacity [11], and their clinical utility in the general population is therefore presently low, at best. But quite a few of them are promising candidates for risk prediction in the future, if they survive such tests.

\subsection{Sources of biomarkers}

In this issue, biomarkers of various origins are reviewed. For risk prediction purposes, it does not matter much in which organ or cell type the biomarker is produced. But from the perspective of understanding the pathophysiology of cardiovascular disease, it may be purposeful to subdivide biomarkers according to their source. This article focuses on the role of biomarkers originating from the myocardium in risk prediction.

Myocardial biomarkers have been researched mainly within the scope of prediction of events in heart failure patients, in patients with acute coronary syndromes or those undergoing related procedures, and in small patient samples with less common diseases. Myocardial biomarkers may also be important for risk prediction in the community, mainly for prediction of incident heart failure, but also for prediction of ischemic heart disease, arrhythmias, or other adverse cardiac events. The general population setting will be the focus of this article.

In the heart, one third of all cells are cardiomyocytes, but these take up $75 \%$ of the volume. Consequently, two thirds of all cells are interstitial non-myocytes, mainly endothelial cells, vascular smooth muscle cells, fibroblasts and myofibroblasts, and macrophages and mast cells [12]. A selection of promising biomarkers from the cardiomyocyte and non-cardiomyocyte compartments are discussed separately in the following (Table).

\section{Myocardial biomarkers reflecting the cardiomyocyte compartment}

\subsection{Troponins}

Cardiac troponins are located on the thin filaments in the sarcomere which, activated by $\mathrm{Ca}^{2+}$, generate the contractile force of the heart. Cardiac troponins circulating in peripheral blood have a widespread clinical use as a tool for diagnosing myocardial damage, mainly that from myocardial infarctions. The recent universal definition of myocardial infarction relies heavily on increased circulating cardiac troponin levels [13]. Circu- 
Table 1

\begin{tabular}{ll}
\hline Cardiomyocyte compartment & Non-cardiomyocyte compartment \\
\hline Troponin-I and -T & Interleukin-6 and -10 \\
Natriuretic peptides ANP, BNP \& NTproBNP & Myocyte chemoattractant protein-1 \\
ST2 & Transforming growth factor- $\beta$ \\
Growth-differentiation factor-15 & Galectin-3 \\
Chromogranin-A & Connective tissue growth factor \\
Osteoprotegerin & Tumour necrosis factor $\alpha$ \\
Heart-type fatty-acid-binding protein & Matrix metalloproteinase-9 \\
Myosin light chain-I & Tissue inhibitor of metalloproteinases-1 \\
Creatine kinase type MB & Collagen propeptides PIIINP, PICP \& ICTP \\
Myoglobin & \\
\hline
\end{tabular}

lating troponin levels have been demonstrated to predict subsequent left ventricular systolic dysfunction [14] and mortality [15] in patients with acute coronary syndromes.

Myocardial damage identified by circulating cardiac troponins may be of prognostic importance also in the absence of an acute myocardial infarction. Circulating troponin levels may predict mortality in a variety of other clinical settings, such as acute decompensated heart failure [16-18] and chronic stable heart failure [19-22] but also in patients with end-stage renal disease without overt heart disease [23], as well as in apparently healthy people in the commmunity [24].

Troponin-I is one of very few myocardial biomarkers (NTproBNP is another) that improves risk discrimination of subsequent cardiovascular events in addition to established risk factors in the general population [11, 25].

This has led to a shift in the view of cardiac troponins, from specific identifiers of myocardial infarction to general indicators of myocardial damage [26]. Numerous sources of elevated troponin levels have been identified in persons angiographically free from coronary artery disease $[27,28]$. Most involve an oxygen supply/demand mismatch, such as in tachycardia, physical exertion, severe aortic stenosis, left ventricular hypertrophy, severe heart failure or anemia, whereas the cardiomyocyte damage mechanism may be less obviously ischemia-related in other cases, such as sepsis, myocarditis, pericarditis, diabetic ketoacidosis, or myocardial contusion [27,28]. Troponin levels are also increased in persons with renal disease, which presents a challenge when using troponins for risk prediction in that setting [29].

Increased circulating troponin levels are generally assumed to reflect severe cardiomyocyte injury or death [30], but may also signify leakage of unbound sarcoplasmatic troponin through damaged membranes [31], or may be the result of troponin assays detecting cleaved troponin peptides [32], degrad- ed as a result of a higher rate of normal troponin turnover or because of acute cardiomyocyte injury. In ischemia/reperfusion injury, two proteases suggested to be responsible for troponin cleavage and contractile dysfunction are calpain $\left(\mathrm{a} \mathrm{Ca}^{2+}\right.$-activated protease) [33] and matrix metalloproteinase-2 [34].

\subsection{Natriuretic peptides and $S T 2$}

Atrial and brain natriuretic peptides (ANP, BNP) are primarily produced in the heart; ANP mainly in the atria and BNP mainly in the ventricles, although all chambers have the possibility to produce both peptides [35]. $\mathrm{BNP}$ and the N-terminal fragment of its prohormone (NTproBNP) are mainly thought of and used clinically as indicators of left and right ventricular pressures, but may in fact rise in response to numerous stimuli, including sepsis, burn injury, or strenuous physical exercise [36]. In fact, in one study of patients with shock, NTproBNP did not correlate with ventricular filling pressures [37], but high NTproBNP levels nevertheless predicted mortality in this setting.

Higher NTproBNP levels have repeatedly been demonstrated to predict mortality also in a variety of other settings, such as in persons with acute coronary syndromes [38-40], stabile coronary disease [41,42], and in the general population [25,43,44], independently of most established risk factors. A dose-response relation has been demonstrated; the higher NTproBNP, the higher the risk $[41,43]$. The main use of BNP or NTproBNP in risk prediction today is in patients with heart failure $[45,46]$ or dyspnea in the emergency setting [47].

NTproBNP is one of the few myocardial biomarkers that have been demonstrated to improve discrimination of risk for cardiovascular events above and beyond established risk factors in apparently healthy persons $[11,25]$. When interpreting levels of natriuretic peptides, it should be noted that persons with renal disease may have higher levels (due to reduced clearance 
or increased production) [48], and obese people may have lower levels [49].

In response to stretch, cardiomyocytes also produce the interleukin-1 receptor family member ST2. Higher levels of the truncated, circulating form of ST2 have been demonstrated in patients with acute heart failure, and predict mortality in patients with acute coronary syndromes [50], dyspnea [51] or acute [52] or chronic heart failure [53]. ST2 expression is stimulated by interleukin-33 produced by stretched fibroblasts, and may thus be a marker for the cross-talk between fibroblasts and cardiomyocytes in response to mechanical overload, and may have a role similar to BNP [52]. The role for ST2 in risk prediction in asymptomatic individuals remains to be determined.

\subsection{Hormones}

Growth-differentiation factor-15 (GDF-15; also known as macrophage-inhibitory cytokine-1, placental bone morphogenetic protein, placental transforming growth factor- $\beta$, and nonsteroidal antiinflammatory drug-activated gene-1) is a member of the transforming growth factor- $\beta$ cytokine superfamily. It is produced in several tissues, including activated macrophages and cardiomyocytes. In response to ischemic injury and other stressors, cardiomyocyte production of GDF-15 increases [54], and it has been suggested to have antiapoptotic, antihypertrophic, and antiremodeling effects. In one case-control study, higher plasma GDF-15 levels predicted subsequent cardiovascular events [55]. Higher circulating GDF-15 levels also predict adverse outcome in persons with acute myocardial infarction [56,57] or chronic heart failure [58]. The cellular source of the circulating GDF-15 in different settings remains to be determined, but the cardiomyocyte is a primary suspect.

Another interesting biomarker is chromogranin-A ( $\mathrm{CgA})$, which is a prohormone that is cleaved to form several peptides with regulatory properties [59], some of which may be cardioinhibitory [60]. $\mathrm{CgA}$ is stored in the same granulae as BNP in cardiomyocytes of heart failure patients [60], and heart failure patients have increased circulating levels of $\mathrm{CgA}$ [60]. High circulating $\mathrm{CgA}$ levels after myocardial infarction predict worse prognosis [61,62]. No studies have investigated the predictive capacity of $\mathrm{CgA}$ in the general population.

Osteoprotegerin is a soluble member of the TNF receptor superfamily with many effects, including bone metabolic, endocrine and immune functions, and its is produced in cardiomyocytes [63]. Higher levels predict adverse prognosis in acute coronary syndromes $[64,65]$ as well as in the general population $[66,67]$.

\subsection{Other cardiomyocyte biomarkers}

Heart-type fatty-acid-binding protein (H-FABP) is a cytosolic protein produced by cardiomyocytes. Elevated $\mathrm{H}-\mathrm{FABP}$ levels are observed in heart failure patients [68], and may signify adverse prognosis in patients with heart failure [68] or acute coronary syndrome [69,70].

More than a decade ago, elevated levels of circulating myosin light chains were observed to predict adverse events in patients with chest pain [71]. The subtype myosin light chain-I (MLC-I) has been demonstrated to predict adverse prognosis in patients with chest pain [72] or heart failure [68]. Although other cardiomyocyte biomarkers such as creatine kinase type MB (CK-MB) [73,74] and myoglobin [75,76] are successfully used clinically to diagnose myocardial infarction and predict mortality in patients with chest pain, their use has been overshadowed by the introduction of troponin measurements. It should be noted that although troponin-I has been demonstrated to be a useful predictor of cardiovascular events in the general population [25], CK-MB and myoglobin have not been investigated with that question in mind. These biomarkers may hence require more study in that setting, as discriminative capacity of a biomarker for risk of adverse events determined in the setting of acute chest pain cannot be directly transposed to the general population. Myoglobin is likely the least promising of these two for the purpose of risk prediction in the general population, because of its rapid clearance from peripheral blood and because it is not cardiomyocyte specific but is also produced by oxidative skeletal muscles. The roles for MLC-I and H-FABP in risk prediction in the general population are also unknown. See the Figure for a schematic illustration of some of the relations described.

\section{Myocardial biomarkers reflecting the non-cardiomyocyte compartment}

\subsection{Inflammatory, macrophage and fibroblast substances}

Relations of circulating inflammatory biomarkers to subsequent cardiovascular events have been known for a decade, and have been demonstrated numerous times for C-reactive protein, but also for other biomarkers and less specific measures such as the erythrocyte sedimentation rate [77]. The main source of the circulating 


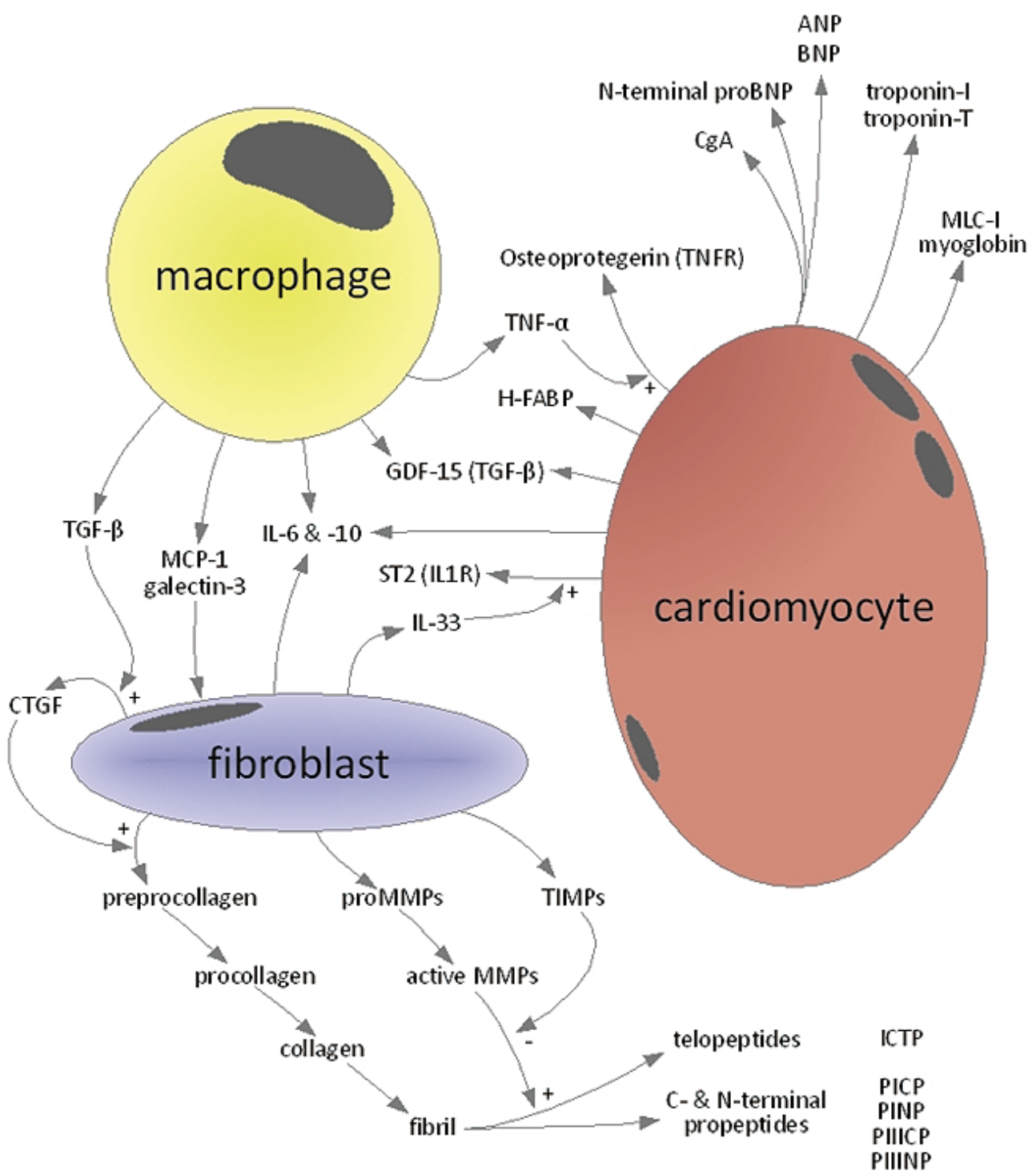

Fig. 1. Sources of and relations between some promising myocardial biomarkers.

C-reactive protein is the liver, as is the case for several other inflammatory biomarkers. The contribution of the inflammatory molecules produced in the myocardium to the circulating levels is not known, but is likely small for many of these biomarkers. Non-cardiomycytes are the main producers of inflammatory biomarkers in the myocardium, with the exception of a few, including interleukin (IL)-6 [78].

Circulating levels of IL-6 predicts subsequent stroke, coronary events [79], and heart failure $[79,80]$ in general population samples. IL-6 produced in peripheral arteries contribute significantly to circulating IL-6 in heart failure patients [81], but the contribution of IL-6 produced in the myocardium [78] to circulating levels in the general population is not known.

In heart failure patients treated with intravenous immunoglobulin, left ventricular systolic function improved and circulating interleukin-10 levels increased [82], indicating a protective role for this antiinflammatory cytokine. The predictive capacity in the general population of this and other interleukins having the myocardium as a major source of origin remains to be clarified.

Macrophages have been invoked in many disease processes, especially in fibrosis development. Hence, the cardiac macrophages have been suggested to play 
a role in cardiac fibrosis and dysfunction by stimulating fibroblasts, and myocyte chemoattractant protein (MCP)-1 [83], transforming growth factor (TGF)$\beta$ [83] and galectin-3 [84] have been suggested as relevant markers of this process. Higher circulating galectin-3 levels have been demonstrated in heart failure patients, and these may signify an adverse prognosis [85]. Connective tissue growth factor (CTGF) is a cysteine-rich protein induced by TGF- $\beta$ in connective tissue cells. CTGF can trigger many of the cellular processes underlying fibrosis, such as cell proliferation, adhesion, migration and the synthesis of extracellular matrix [86,87]. The role of most these biomarkers in prediction of events remains to be clarified.

Macrophages in failing hearts have been demonstrated to produce tumour necrosis factor- $\alpha$ (TNF- $\alpha)$, but no such production is found in normal hearts [88]. Circulating TNF- $\alpha$ [79] and production of TNF- $\alpha$ by peripheral blood mononuclear cells [80] predict incidence of heart failure and coronary events in the general population. The importance of the TNF- $\alpha$ produced by the myocardium vs. other sources is unknown, as is its role in risk prediction. Its role as a drug target in heart failure patients has not been successful hitherto [89].

\subsection{Extracellular matrix peptides}

Derangements in the cardiac extracellular matrix and its turnover have recently come into focus as key elements in the pathogenesis of cardiac remodeling and disease, such as cardiac fibrosis, ischemia, arrhythmias and remodeling/failure, and have emerged as possible tools for monitoring disease and targets for intervention. All macroscopic cardiac changes involve extracellular matrix remodeling. Collagen breakdown in the matrix is under the control of a balance between the matrix-degrading matrix metalloproteinases (MMPs), and their inhibitors, the tissue inhibitors of metalloproteinases (TIMPs). Extracellular matrix metabolism can be assessed by measuring circulating levels or activity of MMPs and TIMPs, or by assaying levels of procollagen peptides derived from assembly and/or breakdown of collagen fibrils [90]. This approach is moleculespecific, but organ-unspecific, as these biomarkers are produced by many different organs, including but not exclusive to the myocardium. Correlations between cardiac and circulating levels of some of these matrix biomarkers are excellent [91-93], but the markers best reflecting the cardiac matrix metabolism remain to be established among the nearly forty identified MMPs, TIMPs and procollagen peptides. Thus, the relations described below cannot be said to exclusively reflect myocardial sources of the markers, until further evidence is at hand.

All major cardiovascular disease risk factors - such as age, male sex, smoking, dyslipidemia, diabetes, hypertension, obesity and inflammation - have been related to altered levels of circulating MMPs, TIMPs or procollagen peptides. These relations have mainly been established in small patient samples, but for MMP-9 and TIMP-1 also in large community-based samples [94-96]. In two such samples, circulating MMP-9 and TIMP1 levels have also been related to LV hypertrophy [94-96], and TIMP-1 levels inversely related to LV systolic function $[94,96]$.

Several of these markers have bee demonstrated to predict adverse outcome in various patient settings. In persons with angina pectoris, higher circulating MMP9 levels predict rapid coronary luminal diameter reduction [97] and fatal cardiovascular events [98]. Also higher TIMP-1 levels predict an increased risk of myocardial infarction [99] and mortality $[99,100]$ in angina patients. The increased extracellular matrix turnover indicated by these circulating marker levels may be causal for both plaque growth (collagen accumulation) and plaque instability (collagen depletion in the fibrous cap of a vulnerable plaque).

During an acute coronary syndrome, a cascade of MMPs are expressed and activated in the myocardium, mainly in and near the infarcted area, which gives rise to collagen degradation and replacement and TIMP activation. Some matrix markers (mainly known for TIMP-1 and the collagen propeptides PIIINP and PICP) can be found in peripheral blood during many weeks after an acute coronary syndrome. High circulating levels of PIIINP predict mortality [101,102], systolic dysfunction [103] and heart failure [102] after a myocardial infarction; and high PICP levels also portend an adverse outcome after myocardial infarction [104, 105].

In persons with chronic heart failure, elevated PIIINP levels have repeatedly been demonstrated to predict poor outcome [91,106,107], and higher PICP [91, 106] and ICTP [106] levels have also indicated a poor prognosis in a few reports. In both the settings of an acute coronary syndrome and heart failure, subsequent normalization of circulating PIIINP levels corresponds to a better prognosis $[103,106]$.

Studies of the predictive value of matrix biomarkers in the general population is limited. In one small study of vitamin D-deficient Bangladeshi East Londoners, plasma MMP-9 level was a predictor of subse- 
quent ischemic heart disease and/or hypertension incidence [108].

The use of extracellular matrix regulators as drug targets is promising. Several conventional drugs influence extracellular matrix metabolism, most notably thrombolytic therapy, which powerfully stimulates MMP expression and collagen degradation [109-112]. Notable are also MMP-9-lowering effect of statins [113116] and matrix effects of thiazolidinediones [117, 118], angiotensin-converting enzyme inhibitors [119124], angiotensin II-receptor antagonists [125,126], and spironolactone $[106,124]$. In a small study of heart failure patients, thalidomide treatment lowered MMP-2 and also improved LV systolic function [127].

Pharmaceutical companies have shown great interest in synthetic MMP inhibitors because of potential for use in a broad spectrum of diseases, including cancer, periodontitis, pulmonary disease and cardiovascular diseases. An early clinical trial with an MMP inhibitor (batimastat)-eluting coronary stent did not show beneficial effects of the treatment [128]. The most promising setting and timing for the right (specific or broad-spectrum) MMP inhibitors remain to be identified.

\section{Taking myocardial biomarkers from bench to bedside}

A number of issues should be considered when choosing myocardial biomarkers for risk prediction. Properties sought in a new myocardial biomarker should include scientific proof of a primary role for the biomarker as mediator of a cardiac disease process; demonstration of a correlation between circulating levels and myocardial levels of the marker; consistent evidence that circulating levels of the biomarker are elevated in persons who subsequently suffer a clinically relevant adverse outcome; stability of the biomarker in stored blood samples; reasonable physiological variability; and accessibility of assays with small measurement error. Criteria for usefulness of a new biomarker have been proposed [10], which include a precise, accessible and reasonably priced assay; the observation that information carried in the biomarker is not known from other clinical data; and demonstration of a beneficial decision making by using the biomarker.

To this list should be added the need for demonstration of added power of a new marker to discriminate between persons who will have an adverse outcome from those who will not, above and beyond a mod- el with established risk factors [11]. Discriminative capacity has traditionally been investigated using the area under the receiver operating characteristics curve of sensitivity and specificity (the C-statistic). Investigating differences in $\mathrm{C}$-statistics between two models is a conservative method, and will often leave the investigator with a case of a statistically significant and independent relation of a new marker to an outcome, with a better model fit, but with a non-significant difference in C-statistics between a smaller model with established risk factors and a bigger model which also incorporates the new marker [129]. As a solution to this problem, two new, simple measures of added discriminatory capacity have been proposed [11], the net reclassification improvement (NRI) and the integrated discrimination improvement (IDI). NRI measures the reclassification of persons from one risk category to another by addition of the new marker to a model with established risk factors. If all persons risk are on average better classified (the persons ends up in a more correct risk class) by the model with the new marker, NRI is positive. The NRI is highly attractive from a clinical point of view, because it assumes that there exist a priori meaningful risk categories, which means that the investigator must decide which the most clinically relevant risk thresholds are (likely those thresholds that influence treatment decisions). If a person's risk is more correctly classified according to these thresholds by measuring a new marker, the marker by definition has clinical importance. The IDI is similar, but does not consider risk thresholds.

Two myocardial biomarkers have passed these tests of usefulness for risk prediction in the general population to date, troponin-I and NTproBNP [25]. Among the biomarkers reviewed in this article and those that were not mentioned, more may find usefulness by this definition in the future; if not in the general population, then perhaps in specific patient settings. If a new biomarker does not pass the tests mentioned above, it may still be useful for the understanding of pathophysiology, but it should not be marketed as a clinically useful marker for risk prediction.

\section{References}

[1] European Society of Cardiology, European Heart Network, European Commission, World Health Organization. The European Heart Health Charter. 6-12-2007. Ref Type: Internet Communication.

[2] W.B. Kannel, D.R. Gagnon and L.A. Cupples, Epidemiology of sudden coronary death: population at risk, Can J Cardiol 6(10) (Dec 1990), 439-444. 
[3] S.E. Sheifer, T.A. Manolio and B.J. Gersh, Unrecognized Myocardial Infarction, Ann Intern Med 135(9) (6 Nov 2001), 801-811.

[4] C. Ebeling Barbier, T. Bjerner, L. Johansson, L. Lind and H. Ahlstrom, Myocardial Scars More Frequent Than Expected: Magnetic Resonance Imaging Detects Potential Risk Group, Journal of the American College of Cardiology 48(4) (15 Aug 2006), 765-771.

[5] W.B. Kannel, T.R. Dawber, A. Kagan, N. Revotskie and J. Stokes, III., Factors of risk in the development of coronary heart disease - six year follow-up experience. The Framingham Study, Ann Intern Med 55 (Jul 1961), 33-50.

[6] A.D. Lopez, C.D. Mathers, M. Ezzati, D.T. Jamison and C.J. Murray, Global and regional burden of disease and risk factors, 2001: systematic analysis of population health data, The Lancet 367(9524), 1747-1757.

[7] P.N. Hopkins and R.R. Williams, A survey of 246 suggested coronary risk factors, Atherosclerosis 40(1) (1981), 1-52.

[8] R.S. Vasan, L.M. Sullivan, P.W. Wilson, C.T. Sempos, J. Sundstrom, W.B. Kannel et al., Relative importance of borderline and elevated levels of coronary heart disease risk factors, Ann Intern Med 142(6) (15 Mar 2005), 393-402.

[9] T.A. Gaziano, C.R. Young, G. Fitzmaurice, S. Atwood and J.M. Gaziano, Laboratory-based versus non-laboratorybased method for assessment of cardiovascular disease risk: the NHANES I Follow-up Study cohort, Lancet 371(9616) (15 Mar 2008), 923-931.

[10] D.A. Morrow and J.A. de Lemos. Benchmarks for the Assessment of Novel Cardiovascular Biomarkers, Circulation 115(8) (27 Feb 2007), 949-952.

[11] M.J. Pencina, R.B. D'Agostino, Sr., R.B. D’Agostino, Jr. and R.S. Vasan, Evaluating the added predictive ability of a new marker: from area under the ROC curve to reclassification and beyond, Stat Med 27(2) (30 Jan 2008), 157-172.

[12] K.T. Weber and C.G. Brilla, Pathological hypertrophy and cardiac interstitium. Fibrosis and renin- angiotensinaldosterone system, Circulation 83(6) (1 Jun 1991), 1849.

[13] K. Thygesen, J.S. Alpert and H.D. White, on behalf of the Joint ESC/ACCF/AHA/WHF Task Force for the Redefinition of Myocardial Infarction, TASK FORCE MEMBERS: Chairpersons: Kristian Thygesen (Denmark), Biomarker Group: Allan S. Jaffe CU, et al. Universal Definition of Myocardial Infarction, Circulation 116(22) (27 Nov 2007), 2634-2653.

[14] H. Steen, S. Futterer, C. Merten, C. Junger, H.A. Katus and E. Giannitsis, Relative role of NT-pro BNP and cardiac troponin $\mathrm{T}$ at 96 hours for estimation of infarct size and left ventricular function after acute myocardial infarction, J Cardiovasc Magn Reson 9(5) (2007), 749-758.

[15] D.A. Morrow, C.P. Cannon, N. Rifai, M.J. Frey, R. Vicari, N. Lakkis et al., Ability of Minor Elevations of Troponins I and T to Predict Benefit From an Early Invasive Strategy in Patients With Unstable Angina and Non-ST Elevation Myocardial Infarction: Results From a Randomized Trial, JAMA: the Journal of the American Medical Association 286(19) (21 Nov 2001), 2405-2412.

[16] J.J. You, P.C. Austin, D.A. Alter, D.T. Ko and J.V. Tu, Relation between cardiac troponin I and mortality in acute decompensated heart failure, American Heart Journal 153(4) (Apr 2007), 462-470.

[17] C.H. Del Carlo, A.C. Pereira-Barretto, C. Cassaro-Strunz, M.D.R. Latorre and J.A.F. Ramires, Serial measure of cardiac troponin $\mathrm{T}$ levels for prediction of clinical events in decompensated heart failure, Journal of Cardiac Failure 10(1) (Feb 2004), 43-48.
[18] W.F. Peacock, I.V, T. De Marco, G.C. Fonarow, D. Diercks, J. Wynne, F.S. Apple et al., Cardiac Troponin and Outcome in Acute Heart Failure, N Engl J Med 358(20) (15 May 2008), 2117-2126

[19] R. Latini, S. Masson, I.S. Anand, E. Missov, M. Carlson, T. Vago et al., Prognostic Value of Very Low Plasma Concentrations of Troponin T in Patients With Stable Chronic Heart Failure, Circulation 116(11) (11 Sep 2007), 1242-1249.

[20] W.L. Miller, K.A. Hartman, M.F. Burritt, D.E. Grill, R.J. Rodeheffer, J.C. Burnett, Jr. et al., Serial Biomarker Measurements in Ambulatory Patients With Chronic Heart Failure: The Importance of Change Over Time, Circulation 116(3) (17 Jul 2007), 249-257.

[21] Y. Sato, T. Yamada, R. Taniguchi, K. Nagai, T. Makiyama, H. Okada et al., Persistently Increased Serum Concentrations of Cardiac Troponin T in Patients With Idiopathic Dilated Cardiomyopathy Are Predictive of Adverse Outcomes, Circulation 103(3) (23 Jan 2001), 369-374.

[22] T.B. Horwich, J. Patel, W.R. MacLellan and G.C. Fonarow, Cardiac Troponin I Is Associated With Impaired Hemodynamics, Progressive Left Ventricular Dysfunction, and Increased Mortality Rates in Advanced Heart Failure, Circulation 108(7) (19 Aug 2003), 833-838.

[23] C. deFilippi, S. Wasserman, S. Rosanio, E. Tiblier, H. Sperger, M. Tocchi et al., Cardiac Troponin T and C-Reactive Protein for Predicting Prognosis, Coronary Atherosclerosis, and Cardiomyopathy in Patients Undergoing Long-term Hemodialysis, JAMA: the Journal of the American Medical Association 290(3) (16 Jul 2003), 353-359.

[24] B. Zethelius, N. Johnston and P. Venge, Troponin I as a Predictor of Coronary Heart Disease and Mortality in 70-YearOld Men: A Community-Based Cohort Study, Circulation 113(8) (28 Feb 2006), 1071-1078.

[25] B. Zethelius, L. Berglund, J. Sundstrom, E. Ingelsson, S. Basu, A. Larsson et al., Use of Multiple Biomarkers to Improve the Prediction of Death from Cardiovascular Causes, $N$ Engl J Med 358(20) (15 May 2008), 2107-2116.

[26] R.E. Fromm, Jr., Cardiac troponins in the intensive care unit: common causes of increased levels and interpretation, Crit Care Med 35(2) (Feb 2007), 584-588.

[27] N. Mahajan, Y. Mehta, M. Rose, J. Shani and E. Lichstein, Elevated troponin level is not synonymous with myocardial infarction, International Journal of Cardiology 111(3) (28 Aug 2006), 442-449.

[28] T.K. Bakshi, M.K.F. Choo, C.C. Edwards, A.G. Scott, H.H. Hart and G.P. Armstrong, Causes of elevated troponin I with a normal coronary angiogram, Internal Medicine Journal 32(11) (30 Nov 2002), 520-525.

[29] B.J. Freda, W.H.W. Tang, F. Van Lente, W.F. Peacock and G.S. Francis, Cardiac troponins in renal insufficiency: Review and clinical implications, Journal of the American College of Cardiology 40(12) (18 Dec 2002), 2065-2071.

[30] T.J. Wang, Significance of Circulating Troponins in Heart Failure: If These Walls Could Talk, Circulation 116(11) (11 Sep 2007), 1217-1220.

[31] J.P. Bertinchant, E. Robert, A. Polge, C. Marty-Double, P. Fabbro-Peray, S. Poirey et al., Comparison of the diagnostic value of cardiac troponin I and T determinations for detecting early myocardial damage and the relationship with histological findings after isoprenaline-induced cardiac injury in rats, Clinica Chimica Acta 298(1-2) (Aug 2000), 13-28.

[32] J.L. McDonough, D.K. Arrell and J.E. Van Eyk, Troponin I Degradation and Covalent Complex Formation Accompanies 
Myocardial Ischemia/Reperfusion Injury, Circ Res 84(1) (22 Jan 1999), 9-20.

[33] A. Maekawa, J.K. Lee, T. Nagaya, K. Kamiya, K. Yasui, M. Horiba et al., Overexpression of calpastatin by gene transfer prevents troponin I degradation and ameliorates contractile dysfunction in rat hearts subjected to ischemia/reperfusion, Journal of Molecular and Cellular Cardiology 35(10) (Oct 2003), 1277-1284.

[34] W. Wang, C.J. Schulze, W.L. Suarez-Pinzon, J.R.B. Dyck, G. Sawicki and R. Schulz, Intracellular Action of Matrix Metalloproteinase-2 Accounts for Acute Myocardial Ischemia and Reperfusion Injury, Circulation 106(12) (17 Sep 2002), 1543-1549.

[35] H. Yasue, M. Yoshimura, H. Sumida, K. Kikuta, K. Kugiyama, M. Jougasaki et al., Localization and mechanism of secretion of B-type natriuretic peptide in comparison with those of A-type natriuretic peptide in normal subjects and patients with heart failure, Circulation 90(1) (Jul 1994), 195-203.

[36] D. Konig, O. Neubauer, L. Nics, N. Kern, A. Berg, E. Bisse et al., Biomarkers of exercise-induced myocardial stress in relation to inflammatory and oxidative stress, Exerc Immunol $\operatorname{Rev} 13$ (2007), 15-36.

[37] J. Januzzi, A. Morss, R. Tung, R. Pino, M. Fifer, B.T. Thompson et al., Natriuretic peptide testing for the evaluation of critically ill patients with shock in the intensive care unit: a prospective cohort study, Critical Care 10(1) (2006), R37.

[38] O. Bazzino, J.J. Fuselli, F. Botto, D. Perez de Arenaza, C. Bahit, J. Dadone et al., Relative value of N-terminal probrain natriuretic peptide, TIMI risk score, ACC/AHA prognostic classification and other risk markers in patients with non-STelevation acute coronary syndromes, European Heart Journal 25(10) (2 May 2004), 859-866.

[39] S.K. James, B. Lindahl, A. Siegbahn, M. Stridsberg, P. Venge, P. Armstrong et al., N-Terminal Pro-Brain Natriuretic Peptide and Other Risk Markers for the Separate Prediction of Mortality and Subsequent Myocardial Infarction in Patients With Unstable Coronary Artery Disease: A Global Utilization of Strategies To Open occluded arteries (GUSTO)-IV Substudy, Circulation 108(3) (22 Jul 2003), 275-281.

[40] J.A. de Lemos, D.A. Morrow, J.H. Bentley, T. Omland, M.S. Sabatine, C.H. McCabe et al., The Prognostic Value of BType Natriuretic Peptide in Patients with Acute Coronary Syndromes, N Engl J Med 345(14) (4 Oct 2001), 1014-1021.

[41] C. Kragelund, B. Gronning, L. Kober, P. Hildebrandt and R. Steffensen, N-Terminal Pro-B-Type Natriuretic Peptide and Long-Term Mortality in Stable Coronary Heart Disease, $N$ Engl J Med 352(7) (17 Feb 2005), 666-675.

[42] K. Bibbins-Domingo, R. Gupta, B. Na, A.H.B. Wu, N.B. Schiller and M.A. Whooley, N-Terminal Fragment of the Prohormone Brain-Type Natriuretic Peptide (NT-proBNP), Cardiovascular Events, and Mortality in Patients With Stable Coronary Heart Disease, JAMA: the Journal of the American Medical Association 297(2) (10 Jan 2007), 169-176.

[43] C. Kistorp, I. Raymond, F. Pedersen, F. Gustafsson, J. Faber and P. Hildebrandt, N-Terminal Pro-Brain Natriuretic Peptide, C-Reactive Protein, and Urinary Albumin Levels as Predictors of Mortality and Cardiovascular Events in Older Adults, JAMA: the Journal of the American Medical Association 293(13) (6 Apr 2005), 1609-1616.

[44] T.J. Wang, M.G. Larson, D. Levy, E.J. Benjamin, E.P. Leip, T. Omland et al., Plasma Natriuretic Peptide Levels and the Risk of Cardiovascular Events and Death, $N$ Engl J Med 350(7) (12 Feb 2004), 655-663.
[45] G.C. Fonarow, W.F. Peacock, C.O. Phillips, M.M. Givertz and M. Lopatin, Admission B-Type Natriuretic Peptide Levels and In-Hospital Mortality in Acute Decompensated Heart Failure, Journal of the American College of Cardiology 49(19) (15 May 2007), 1943-1950.

[46] R. Valle, N. Aspromonte, M. Feola, M. Milli, C. Canali, P. Giovinazzo et al., B-Type Natriuretic Peptide Can Predict the Medium-Term Risk in Patients With Acute Heart Failure and Preserved Systolic Function, Journal of Cardiac Failure 11(7) (Sep 2005), 498-503.

[47] A.S. Maisel, P. Krishnaswamy, R.M. Nowak, J. McCord, J.E. Hollander, P. Duc et al., Rapid Measurement of B-Type Natriuretic Peptide in the Emergency Diagnosis of Heart Failure, N Engl J Med 347(3) (18 Jul 2002), 161-167.

[48] L.B. Daniels and A.S. Maisel, Natriuretic Peptides, Journal of the American College of Cardiology 50(25), 2357-2368.

[49] T.J. Wang, M.G. Larson, D. Levy, E.J. Benjamin, E.P. Leip, P.W.F. Wilson et al., Impact of Obesity on Plasma Natriuretic Peptide Levels, Circulation 109(5) (10 Feb 2004), 594-600.

[50] M. Shimpo, D.A. Morrow, E.O. Weinberg, M.S. Sabatine, S.A. Murphy, E.M. Antman et al., Serum Levels of the Interleukin-1 Receptor Family Member ST2 Predict Mortality and Clinical Outcome in Acute Myocardial Infarction, Circulation 109(18) (11 May 2004), 2186-2190.

[51] J.L. Januzzi, Jr., W.F. Peacock, A.S. Maisel, C.U. Chae, R.L. Jesse, A.L. Baggish et al., Measurement of the Interleukin Family Member ST2 in Patients With Acute Dyspnea: Results From the PRIDE (Pro-Brain Natriuretic Peptide Investigation of Dyspnea in the Emergency Department) Study, Journal of the American College of Cardiology 50(7) (14 Aug 2007), 607-613.

[52] S.U. Rehman, T. Mueller and J.L. Januzzi, Jr., Characteristics of the Novel Interleukin Family Biomarker ST2 in Patients With Acute Heart Failure, Journal of the American College of Cardiology 52(18) (28 Oct 2008), 1458-1465.

[53] E.O. Weinberg, M. Shimpo, S. Hurwitz, S.I. Tominaga, J.L. Rouleau and R.T. Lee, Identification of Serum Soluble ST2 Receptor as a Novel Heart Failure Biomarker, Circulation 107(5) (11 Feb 2003), 721-726.

[54] T. Kempf, M. Eden, J. Strelau, M. Naguib, C. Willenbockel, J. Tongers et al., The Transforming Growth Factor-\{beta $\}$ Superfamily Member Growth-Differentiation Factor-15 Protects the Heart From Ischemia/Reperfusion Injury, Circ Res 98(3) (17 Feb 2006), 351-360.

[55] D.A. Brown, S.N. Breit, J. Buring, W.D. Fairlie, A.R. Bauskin, T. Liu et al., Concentration in plasma of macrophage inhibitory cytokine-1 and risk of cardiovascular events in women: a nested case-control study, The Lancet 359(9324) (22 Jun 2002), 2159-2163.

[56] T. Kempf, E. Bjorklund, S. Olofsson, B. Lindahl, T. Allhoff, T. Peter et al., Growth-differentiation factor-15 improves risk stratification in ST-segment elevation myocardial infarction, European Heart Journal 28(23) (1 Dec 2007), 2858-2865.

[57] K.C. Wollert, T. Kempf, T. Peter, S. Olofsson, S. James, N. Johnston et al., Prognostic Value of Growth-Differentiation Factor-15 in Patients With Non-ST-Elevation Acute Coronary Syndrome, Circulation 115(8) (27 Feb 2007), 962-971.

[58] T. Kempf, S. von Haehling, T. Peter, T. Allhoff, M. Cicoira, W. Doehner et al., Prognostic Utility of Growth Differentiation Factor-15 in Patients With Chronic Heart Failure, Journal of the American College of Cardiology 50(11) (11 Sep 2007), 1054-1060. 
[59] L. Taupenot, K.L. Harper and D.T. O'Connor, The Chromogranin-Secretogranin Family,N Engl J Med 348(12) (20 Mar 2003), 1134-1149.

[60] M. Pieroni, A. Corti, B. Tota, F. Curnis, T. Angelone, B. Colombo et al., Myocardial production of chromogranin A in human heart: a new regulatory peptide of cardiac function, European Heart Journal 28(9) (1 May 2007), 1117-1127.

[61] M.E. Estensen, A. Hognestad, U. Syversen, I. Squire, L. Ng, J. Kjekshus et al., Prognostic value of plasma chromogranin A levels in patients with complicated myocardial infarction, Am Heart J 152(5) (Nov 2006), 927-926.

[62] T. Omland, K. Dickstein and U. Syversen, Association between plasma chromogranin a concentration and long-term mortality after myocardial infarction, The American Journal of Medicine 114(1) (Jan 2003), 25-30.

[63] T. Ueland, A. Yndestad, E. Oie, G. Florholmen, B. Halvorsen, S.S. Froland et al., Dysregulated Osteoprotegerin/RANK Ligand/RANK Axis in Clinical and Experimental Heart Failure, Circulation 111(19) (17 May 2005), 2461-2468.

[64] T. Omland, T. Ueland, A.M. Jansson, A. Persson, T. Karlsson, C. Smith et al., Circulating Osteoprotegerin Levels and LongTerm Prognosis in Patients With Acute Coronary Syndromes, Journal of the American College of Cardiology 51(6) (12 Feb 2008), 627-633.

[65] T. Ueland, R. Jemtland, K. Godang, J. Kjekshus, A. Hognestad, T. Omland et al., Prognostic value of osteoprotegerin in heart failure after acute myocardial infarction, $\mathrm{J} \mathrm{Am} \mathrm{Coll}$ Cardiol 44(10) (16 Nov 2004), 1970-1976.

[66] S. Kiechl, G. Schett, G. Wenning, K. Redlich, M. Oberhollenzer, A. Mayr et al., Osteoprotegerin Is a Risk Factor for Progressive Atherosclerosis and Cardiovascular Disease, Circulation 109(18) (11 May 2004), 2175-2180.

[67] W.S. Browner, L.Y. Lui and S.R. Cummings, Associations of Serum Osteoprotegerin Levels with Diabetes, Stroke, Bone Density, Fractures, and Mortality in Elderly Women, J Clin Endocrinol Metab 86(2) (1 Feb 2001), 631-637.

[68] T. Sugiura, H. Takase, T. Toriyama, T. Goto, R. Ueda and Y. Dohi, Circulating Levels of Myocardial Proteins Predict Future Deterioration of Congestive Heart Failure, Journal of Cardiac Failure 11(7) (Sep 2005), 504-509.

[69] M. O’Donoghue, J.A. de Lemos, D.A. Morrow, S.A. Murphy, J.L. Buros, C.P. Cannon et al., Prognostic Utility of HeartType Fatty Acid Binding Protein in Patients With Acute Coronary Syndromes, Circulation 114(6) (8 Aug 2006), 550-557.

[70] J. Ishii, Y. Ozaki, J. Lu, F. Kitagawa, T. Kuno, T. Nakano et al., Prognostic Value of Serum Concentration of Heart-Type Fatty Acid-Binding Protein Relative to Cardiac Troponin T on Admission in the Early Hours of Acute Coronary Syndrome, Clin Chem 51(8) (1 Aug 2005), 1397-1404.

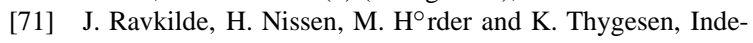
pendent prognostic value of serum creatine kinase isoenzyme MB mass, cardiac troponin $\mathrm{T}$ and myosin light chain levels in suspected acute myocardial infarction: Analysis of 28 months of follow-up in 196 patients, Journal of the American College of Cardiology 25(3) (1 Mar 1995), 574-581.

[72] G.S. Hillis, P. Taggart, D. Wardlaw, L. Hillis, N. Zhao, W.C. Dalsey et al., The relative utility of cardiac troponin I, creatine kinase-MBmass, and myosin light chain-1 in the long-term risk stratification of patients with chest pain, Clin Cardiol 26(3) (Mar 2003), 147-152

[73] J.M. Galla, K.W. Mahaffey, S.K. Sapp, J.H. Alexander, M.T. Roe, E.M. Ohman et al., Elevated creatine kinase-MB with normal creatine kinase predicts worse outcomes in patients with acute coronary syndromes: Results from 4 large clinical trials, American Heart Journal 151(1) (Jan 2006), 16-24.

[74] J.H. Alexander, R.A. Sparapani, K.W. Mahaffey, J.W. Deckers, L.K. Newby, E.M. Ohman et al., Association Between Minor Elevations of Creatine Kinase-MB Level and Mortality in Patients With Acute Coronary Syndromes Without ST-Segment Elevation. JAMA: the Journal of the American Medical Association 283(3) (19 Jan 2000), 347-353.

[75] A. Isakov, I. Shapira, M. Burke and C. Almog, Serum myoglobin levels in patients with ischemic myocardial insult, Arch Intern Med 148(8) (Aug 1988), 1762-1765.

[76] M.C. Kontos, R. Garg, F.P. Anderson, C.S. Roberts, J.P. Ornato, J.L. Tatum et al., Ability of myoglobin to predict mortality in patients admitted for exclusion of myocardial infarction, The American Journal of Emergency Medicine 25(8) (Oct 2007), 873-879.

[77] E. Ingelsson, J. Arnlov, J. Sundstrom and L. Lind, Inflammation, as measured by the erythrocyte sedimentation rate, is an independent predictor for the development of heart failure, $J$ Am Coll Cardiol 45(11) (7 Jun 2005), 1802-1806.

[78] K. Yamauchi-Takihara, Y. Ihara, A. Ogata, K. Yoshizaki, J. Azuma and T. Kishimoto, Hypoxic Stress Induces Cardiac MyocyteûDerived Interleukin-6, Circulation 91(5) (1 Mar 1995), 1520-1524.

[79] M. Cesari, B.W.J.H. Penninx, A.B. Newman, S.B. Kritchevsky, B.J. Nicklas, K. Sutton-Tyrrell et al., Inflammatory Markers and Onset of Cardiovascular Events: Results From the Health ABC Study, Circulation 108(19) (11 Nov 2003), 2317-2322.

[80] R.S. Vasan, L.M. Sullivan, R. Roubenoff, C.A. Dinarello, T. Harris, E.J. Benjamin et al., Inflammatory Markers and Risk of Heart Failure in Elderly Subjects Without Prior Myocardial Infarction: The Framingham Heart Study, Circulation 107(11) (25 Mar 2003), 1486-1491.

[81] T. Tsutamoto, T. Hisanaga, A. Wada, K. Maeda, M. Ohnishi, D. Fukai et al., Interleukin-6 spillover in the peripheral circulation increases with the severity of heart failure, and the high plasma level of interleukin-6 is an important prognostic predictor in patients with congestive heart failure, Journal of the American College of Cardiology 31(2) (1 Feb 1998), 391-398.

[82] L. Gullestad, H. Aass, J.G. Fjeld, L. Wikeby, A.K. Andreassen, H. Ihlen et al., Immunomodulating Therapy With Intravenous Immunoglobulin in Patients With Chronic Heart Failure, OCirculation 103(2) (16 Jan 2001), 220-225.

[83] F. Kuwahara, H. Kai, K. Tokuda, M. Takeya, A. Takeshita, K. Egashira et al., Hypertensive Myocardial Fibrosis and Diastolic Dysfunction: Another Model of Inflammation? Hypertension 43(4) (1 Apr 2004), 739-745.

[84] U.C. Sharma, S. Pokharel, T.J. van Brakel, J.E. van Berlo, J.P.M. Cleutjens, B. Schroen et al., Galectin-3 Marks Activated Macrophages in Failure-Prone Hypertrophied Hearts and Contributes to Cardiac Dysfunction, Circulation 110(19) (9 Nov 2004), 3121-3128.

[85] R.R. van Kimmenade, J.L. Januzzi, Jr., P.T. Ellinor, U.C. Sharma, J.A. Bakker, A.F. Low et al., Utility of aminoterminal pro-brain natriuretic peptide, galectin-3, and apelin for the evaluation of patients with acute heart failure, $J \mathrm{Am}$ Coll Cardiol 48(6) (19 Sep 2006), 1217-1224.

[86] N. Koitabashi, M. Arai, K. Niwano, A. Watanabe, M. Endoh, M. Suguta et al., Plasma connective tissue growth factor is a novel potential biomarker of cardiac dysfunction in patients with chronic heart failure, European Journal of Heart Failure 10(4) (Apr 2008), 373-379.

[87] M.M. Chen, A. Lam, J.A. Abraham, G.F. Schreiner and A.H. 
Joly, CTGF Expression is Induced by TGF- [beta] in Cardiac Fibroblasts and Cardiac Myocytes: a Potential Role in Heart Fibrosis, Journal of Molecular and Cellular Cardiology 32(10) (Oct 2000), 1805-1819.

[88] B. Devaux, D. Scholz, A. Hirche, W.P. Klovekorn and J. Schaper, Upregulation of cell adhesion molecules and the presence of low grade inflammation in human chronic heart failure, European Heart Journal 18(3) (1 Mar 1997), 470479.

[89] D.L. Mann, Targeted Anticytokine Therapy and the Failing Heart, The American Journal of Cardiology 95(11, Supplement 1) (6 Jun 2005), 9-16.

[90] J. Sundstrom and R.S. Vasan, Circulating biomarkers of extracellular matrix remodeling and risk of atherosclerotic events, Curr Opin Lipidol 17(1) (Feb 2006), 45-53.

[91] G. Klappacher, P. Franzen, D. Haab, M. Mehrabi, M. Binder, K. Plesch et al., Measuring Extracellular Matrix Turnover in the Serum of Patients With Idiopathic or Ischemic Dilated Cardiomyopathy and Impact on Diagnosis and Prognosis, The American Journal of Cardiology 75(14) (1 May 1995), 913-918.

[92] R. Querejeta, N. Varo, B. Lopez, M. Larman, E. Artinano, J.C. Etayo et al., Serum Carboxy-Terminal Propeptide of Procollagen Type I Is a Marker of Myocardial Fibrosis in Hypertensive Heart Disease, Circulation 101(14) (11 Apr 2000), 1729-1735.

[93] R. Querejeta, B. Lopez, A. Gonzalez, E. Sanchez, M. Larman, J.L. Martinez Ubago et al., Increased Collagen Type I Synthesis in Patients With Heart Failure of Hypertensive Origin: Relation to Myocardial Fibrosis, Circulation 110(10) (7 Sep 2004), 1263-1268.

[94] J. Sundstrom, J.C. Evans, E.J. Benjamin, D. Levy, M.G. Larson, D.B. Sawyer et al., Relations of plasma total TIMP-1 levels to cardiovascular risk factors and echocardiographic measures: the Framingham heart study, Eur Heart J 25(17) (Sep 2004), 1509-1516.

[95] J. Sundstrom, J.C. Evans, E.J. Benjamin, D. Levy, M.G. Larson, D.B. Sawyer et al., Relations of plasma matrix metalloproteinase- 9 to clinical cardiovascular risk factors and echocardiographic left ventricular measures: the Framingham Heart Study, Circulation 109(23) (15 Jun 2004), 28502856.

[96] J. Hansson, L. Lind, J. Hulthe and J. Sundström, Relations of Serum MMP-9 and TIMP-1 Levels to Left Ventricular Measures and Cardiovascular Risk Factors: A PopulationBased Study, Eur J Cardiovasc Prev Rehabil (2008), in press.

[97] E. Zouridakis, P. Avanzas, R. Arroyo-Espliguero, S. Fredericks and J.C. Kaski, Markers of Inflammation and Rapid Coronary Artery Disease Progression in Patients With Stable Angina Pectoris, Circulation 110(13) (28 Sep 2004), 17471753.

[98] S. Blankenberg, H.J. Rupprecht, O. Poirier, C. Bickel, M. Smieja, G. Hafner et al., Plasma Concentrations and Genetic Variation of Matrix Metalloproteinase 9 and Prognosis of Patients With Cardiovascular Disease, Circulation 107(12) (1 Apr 2003), 1579.

[99] E. Cavusoglu, C. Ruwende, V. Chopra, S. Yanamadala, C. Eng, L.T. Clark et al., Tissue inhibitor of metalloproteinase-1 (TIMP-1) is an independent predictor of all-cause mortality, cardiac mortality, and myocardial infarction, American Heart Journal 151(5) (May 2006), 1101.

[100] E. Lubos, R. Schnabel, H.J. Rupprecht, C. Bickel, C.M. Messow, S. Prigge et al., Prognostic value of tissue inhibitor of metalloproteinase- 1 for cardiovascular death among patients with cardiovascular disease: results from the AtheroGene study, European Heart Journal 27(2) (2 Jan 2006), 150-156.

[101] N.B. Host, L.T. Jensen, P.M. Bendixen, S.E. Jensen, O.G. Koldkjaer and E.E. Simonsen, The Aminoterminal Propeptide of Type III Procollagen Provides New Information on Prognosis After Acute Myocardial Infarction, The American Journal of Cardiology 76(12) (1 Nov 1995), 869-873.

[102] S.H. Poulsen, N.B. Host, S.E. Jensen and K. Egstrup, Relationship Between Serum Amino-Terminal Propeptide of Type III Procollagen and Changes of Left Ventricular Function After Acute Myocardial Infarction, Circulation 101(13) (4 Apr 2000), 1527-1532.

[103] M.G. Modena, R. Molinari, R. Rossi, N. Muia, Jr., A. Castelli, G. Mattioli et al., Modification in serum concentrations of aminoterminal propeptide of type III procollagen in patients with previous transmural myocardial infarction, Am Heart $J$ 135(2 Pt 1) (Feb 1998), 287-292.

[104] S.H. Poulsen, N.B. Host and K. Egstrup, Long-term changes in collagen formation expressed by serum carboxyterminal propeptide of type-I procollagen and relation to left ventricular function after acute myocardial infarction, Cardiology 96(1) (2001), 45-50.

[105] T. Takino, M. Nakamura and K. Hiramori, Circulating levels of carboxyterminal propeptide of type I procollagen and left ventricular remodeling after myocardial infarction, Cardiology 91(2) (1999), 81-86.

[106] F. Zannad, F. Alla, B. Dousset, A. Perez and B. Pitt, Limitation of excessive extracellular matrix turnover may contribute to survival benefit of spironolactone therapy in patients with congestive heart failure: insights from the randomized aldactone evaluation study (RALES). Rales Investigators, $\mathrm{Circu}$ lation 102(22) (28 Nov 2000), 2700-2706.

[107] Y. Sato, K. Kataoka, A. Matsumori, S. Sasayama, T. Yamada, H. Ito et al., Measuring serum aminoterminal type III procollagen peptide, $7 \mathrm{~S}$ domain of type IV collagen, and cardiac troponin $\mathrm{T}$ in patients with idiopathic dilated cardiomyopathy and secondary cardiomyopathy, Heart 78(5) (1 Nov 1997), 505.

[108] P.M. Timms, N. Mannan, G.A. Hitman, K. Noonan, P.G. Mills, D. Syndercombe-Court et al., Circulating MMP9, vitamin D and variation in the TIMP-1 response with VDR genotype: mechanisms for inflammatory damage in chronic disorders? QJM 95(12) (Dec 2002), 787-796.

[109] P. Carmeliet, L. Moons, R. Lijnen, M. Baes, V. Lemaitre, P. Tipping et al., Urokinase-generated plasmin activates matrix metalloproteinases during aneurysm formation, Nat Genet 17(4) (Dec 1997), 439-444.

[110] E. Lee, D.E. Vaughan, S.H. Parikh, A.J. Grodzinsky, P. Libby, M.W. Lark et al., Regulation of Matrix Metalloproteinases and Plasminogen Activator Inhibitor-1 Synthesis by Plasminogen in Cultured Human Vascular Smooth Muscle Cells, Circ Res 78(1)(1 Jan 1996), 44-49.

[111] N.B. Host, S.S. Hansen, L.T. Jensen, D. Husum and J.D. Nielsen, Thrombolytic therapy of acute myocardial infarction alters collagen metabolism, Cardiology 85(5) (1994), 323333.

[112] K.J. Peuhkurinen, L. Risteli, J.T. Melkko, M. Linnaluoto, A. Jounela and J. Risteli, Thrombolytic therapy with streptokinase stimulates collagen breakdown, Circulation 83(6) (Jun 1991), 1969-1975.

[113] K.K. Koh, J.W. Son, J.Y. Ahn, D.K. Jin, H.S. Kim, Y.M. Choi et al., Comparative Effects of Diet and Statin on NO Bioactivity and Matrix Metalloproteinases in Hypercholesterolemic Patients With Coronary Artery Disease, Arterioscler Thromb 
Vasc Biol 22(9) (1 Sep 2002), 19e-23e.

[114] K.K. Koh, J.W. Son, J.Y. Ahn, Y.M. Choi, D.K. Jin, G.S. Park et al., Non-lipid effects of statin on hypercholesterolemic patients established to have coronary artery disease who remained hypercholesterolemic while eating a step-II diet, Coron Artery Dis 12(4) (Jun 2001), 305-311.

[115] A. Kalela, R. Laaksonen, T. Lehtimaki, T.A. Koivu, M. Hoyhtya, T. Janatuinen et al., Effect of pravastatin in mildly hypercholesterolemic young men on serum matrix metalloproteinases, The American Journal of Cardiology 88(2) (15 Jul 2001), 173-175.

[116] K.J. Molloy, M.M. Thompson, E.C. Schwalbe, P.R.F. Bell, A.R. Naylor and I.M. Loftus, Comparison of levels of matrix metalloproteinases, tissue inhibitor of metalloproteinases, interleukins, and tissue necrosis factor in carotid endarterectomy specimens from patients on versus not on statins preoperatively, The American Journal of Cardiology 94(1) (1 Jul 2004), 144-146.

[117] S.M. Haffner, A.S. Greenberg, W.M. Weston, H. Chen, K. Williams and M.I. Freed, Effect of Rosiglitazone Treatment on Nontraditional Markers of Cardiovascular Disease in Patients With Type 2 Diabetes Mellitus, Circulation 106(6) (6 Aug 2002), 679-684.

[118] N. Marx, J. Froehlich, L. Siam, J. Ittner, G. Wierse, A. Schmidt et al., Antidiabetic PPAR \{gamma $\}$-Activator Rosiglitazone Reduces MMP-9 Serum Levels in Type 2 Diabetic Patients With Coronary Artery Disease, Arterioscler Thromb Vasc Biol 23(2) (1 Feb 2003), 283.

[119] J. Diez, C. Laviades, G. Mayor, M.J. Gil and I. Monreal, Increased Serum Concentrations of Procollagen Peptides in Essential Hypertension: Relation to Cardiac Alterations, Circulation 91(5) (1 Mar 1995), 1450-1456.

[120] I. Ebihara, T. Nakamura, N. Shimada and H. Koide, Increased plasma metalloproteinase- 9 concentrations precede development of microalbuminuria in non-insulin-dependent diabetes mellitus, Am J Kidney Dis 32(4) (Oct 1998), 544-550.

[121] C. Laviades, N. Varo, J. Fernandez, G. Mayor, M.J. Gil, I. Monreal et al., Abnormalities of the Extracellular Degradation of Collagen Type I in Essential Hypertension, Circulation 98(6) (11 Aug 1998), 535-540.

[122] M. Matoba, T. Asaji, S. Matsui and N. Takekoshi, Long- term effects of delapril hydrochloride on procollagen type III amino-terminal peptide, left ventricular mass and left ventricular function in hypertensive patients, Jpn Circ J 62(12) (Dec 1998), 900-902.

[123] M. Sasaguri, K. Noda, E. Tashiro, J. Notomo, E. Tsuji, M. Koga et al., The regression of left ventricular hypertrophy by imidapril and the reduction of serum procollagen type III amino-terminal peptide in hypertensive patients, Hypertens Res 23(4) (Jul 2000), 317-322.

[124] A. Sato, H. Takane and T. Saruta, High serum level of procollagen type III amino-terminal peptide contributes to the efficacy of spironolactone and angiotensin-converting enzyme inhibitor therapy on left ventricular hypertrophy in essential hypertensive patients, Hypertens Res 24(2) (Mar 2001), 99-104.

[125] J. Diez, R. Querejeta, B. Lopez, A. Gonzalez, M. Larman and J.L. Martinez Ubago, Losartan-Dependent Regression of Myocardial Fibrosis Is Associated With Reduction of Left Ventricular Chamber Stiffness in Hypertensive Patients, Circulation 105(21) (28 May 2002), 2512-2517.

[126] B. Lopez, R. Querejeta, N. Varo, A. Gonzalez, M. Larman, J.L. Martinez Ubago et al., Usefulness of Serum CarboxyTerminal Propeptide of Procollagen Type I in Assessment of the Cardioreparative Ability of Antihypertensive Treatment in Hypertensive Patients, Circulation 104(3) (17 Jul 2001), 286-291.

[127] L. Gullestad, T. Ueland, J.G. Fjeld, E. Holt, T. Gundersen, K. Breivik et al., Effect of Thalidomide on Cardiac Remodeling in Chronic Heart Failure: Results of a DoubleBlind, Placebo-Controlled Study, Circulation 112(22) (29 Nov 2005), 3408-3414.

[128] C.M. Araujo, G.A. Rando, M.F. Mauro, S.A. Cristovao, I.S. Sanchez, A.A. Salman et al., Batimastat-eluting stent implantation for the treatment of coronary artery disease: results of the Brazilian pilot study, Arq Bras Cardiol 84(3) (Mar 2005), 256-260.

[129] T.J. Wang, P. Gona, M.G. Larson, G.H. Tofler, D. Levy, C. Newton-Cheh et al., Multiple Biomarkers for the Prediction of First Major Cardiovascular Events and Death, $N$ Engl J Med 355(25) (21 Dec 2006), 2631-2639. 


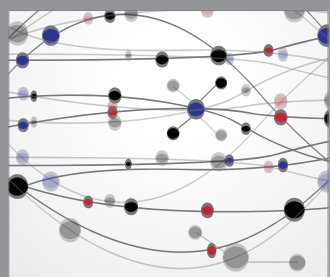

The Scientific World Journal
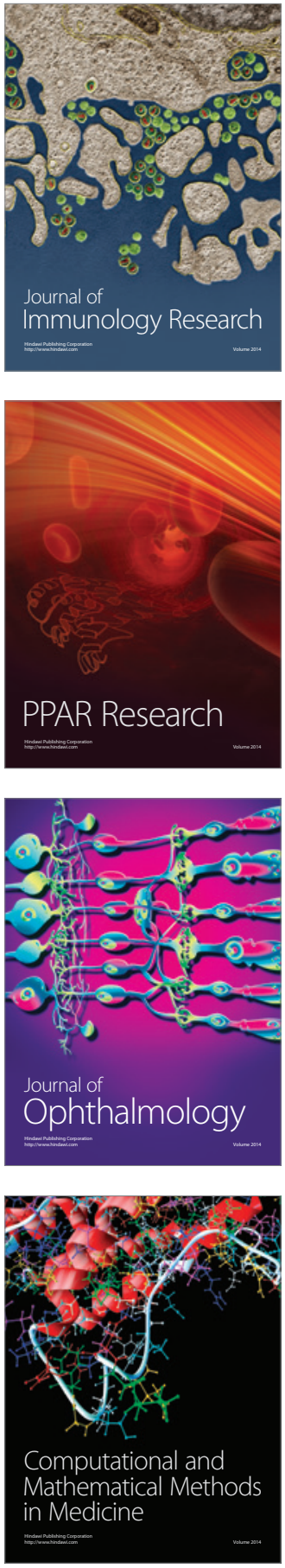

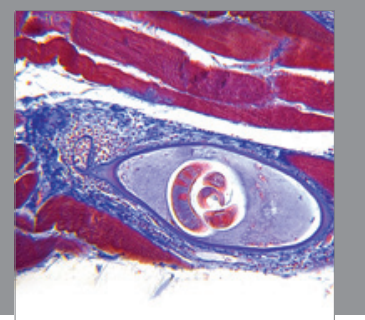

Gastroenterology

Research and Practice
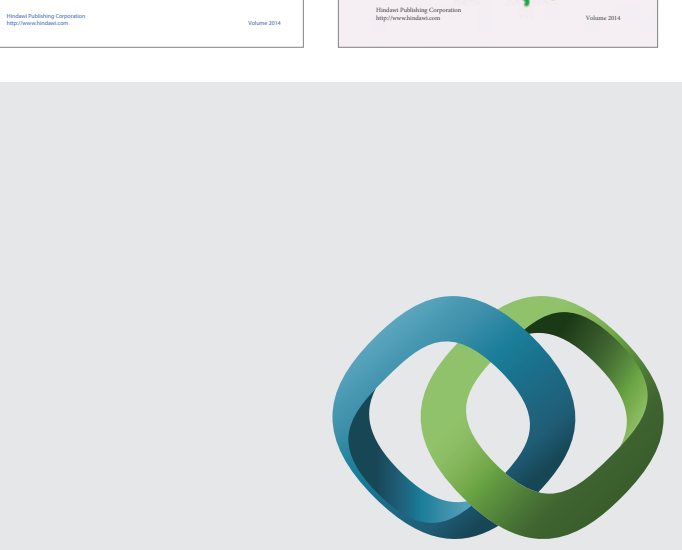

\section{Hindawi}

Submit your manuscripts at

http://www.hindawi.com
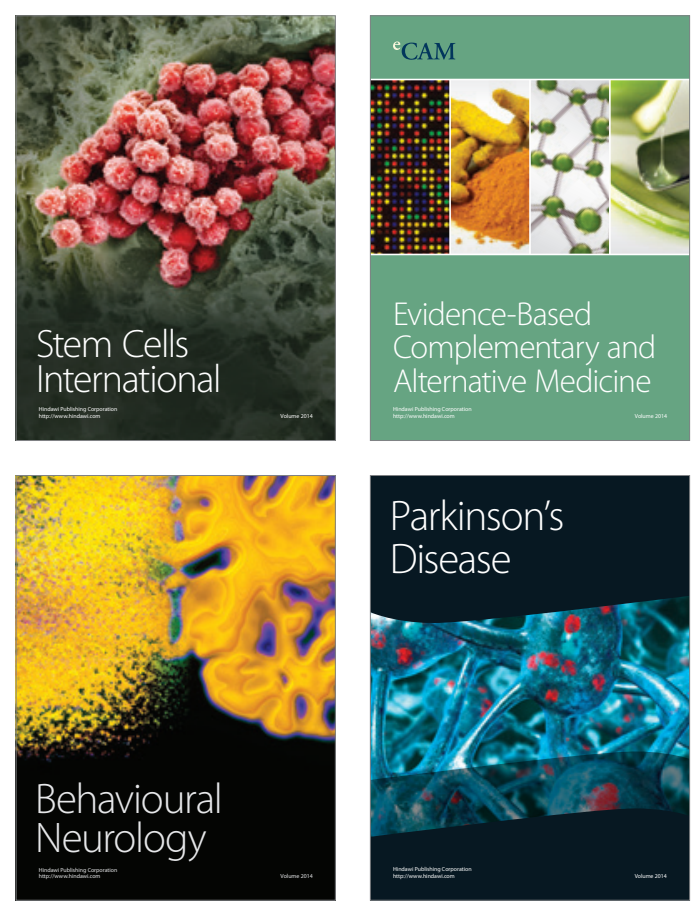

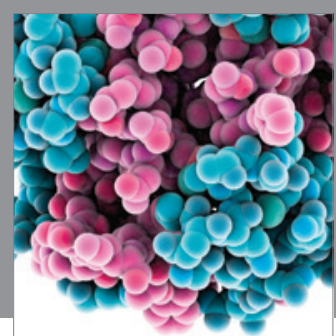

Journal of
Diabetes Research

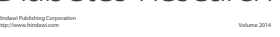

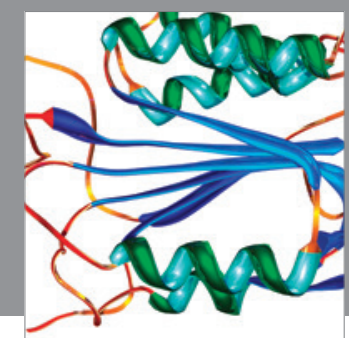

Disease Markers
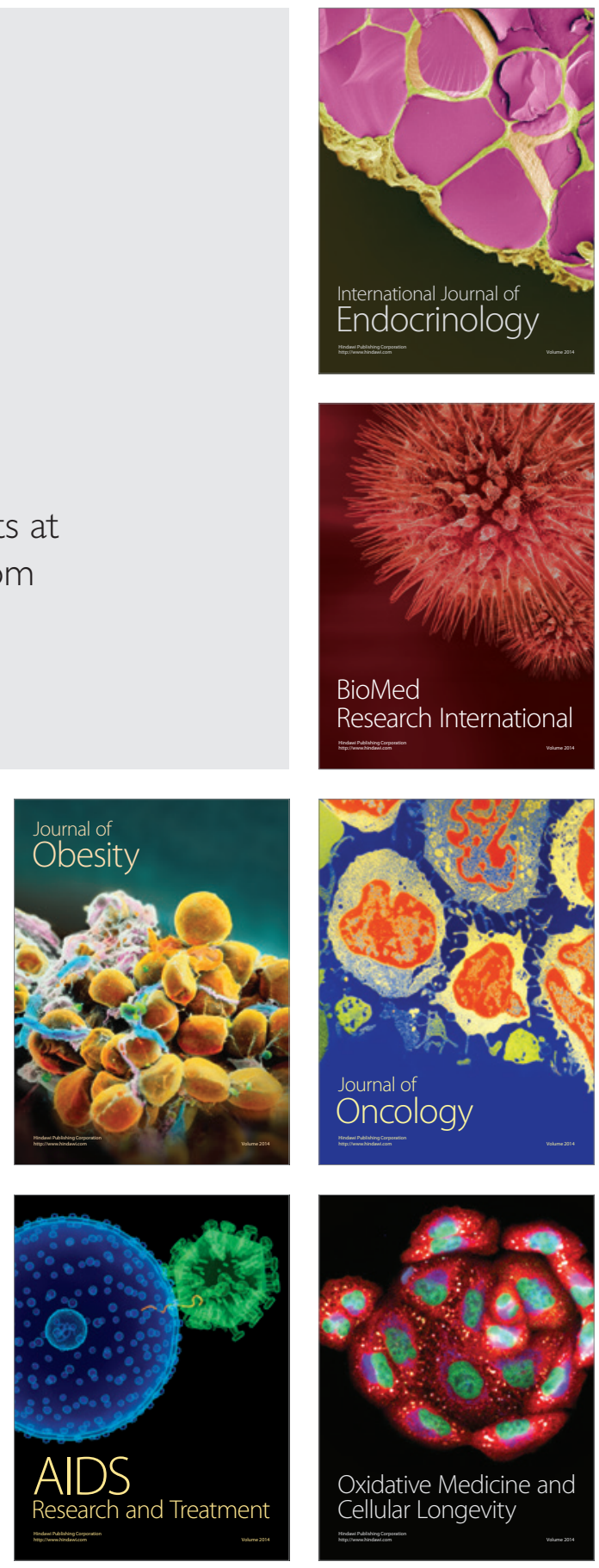